\title{
ASSESSING QUALITY OF HEALTHCARE DELIVERY WHEN MAKING CHOICES: NATIONAL SURVEY ON HEALTH CONSUMERS' DECISION MAKING PRACTICES
}

\author{
Mark Averyl, Allan Cripps, Gary D. Rogers 1,2 \\ 1. School of Medicine, Griffith University', Queensland, Australia \\ 2. School of Medicine, Deakin University, Victoria, Australia
}

Correspondence: mark.avery@griffith.edu.au

\begin{abstract}
OBJECTIVE

Choices and quality decisions made by consumers in relation to their healthcare have been associated with personal experience of those services, interpersonal engagement and reliance on third-party information, as well as the subsequent satisfaction with the service. The purpose of this research was to understand current information sources, determinants of quality discernment and decision-making factors by consumers in the Australian community in relation to healthcare.
\end{abstract}

\section{METHOD}

Conventional content analysis research was undertaken in the form of a national telephone survey of 200 consumers. Open-ended questions were used to elicit information from the general community.

\section{RESULTS}

Reputation and other key interpersonal and structural elements are utilised in determining quality of healthcare services as well as in deployment as key factors in decision-making regarding use of healthcare services. While most respondents valued and used key information about provider relationships, outcomes performance and performance rankings, up to $20 \%$ of respondents did not know or could not identify ways in which they would assess and evaluate the quality of healthcare services.

\section{CONCLUSION}

This research identifies that consumers use a range of information and advice relating to experience, interpersonal engagement and information from third-party sources. If healthcare providers develop clearer communications around their technical, procedural and conduct principles, consumers will be in a better position to evaluate reputation and make decisions about their healthcare needs and the health system.

\section{KEYWORDS}

consumers; consumer engagement; quality; safety; reputation; information needs; sense making. 
Australia is recognised for, and prides itself on, delivering high quality care, however, when asked, the Australian community has little guidance on how to assess quality when making healthcare choices. This research provides insight to the way Australian consumers gather and use information about health service quality and safety and what they want in the future.

Delivering effective quality care is a fundamental goal in providing healthcare services. Quality is a relatively abstract term and can be difficult to define. [1-3] Key considerations of the concept of quality must include how customers or consumers see value and how they express their attitude towards individuals and organisations offering goods and services.

Consumer sovereignty in the health sector is a particularly complex construct [4] in reviewing how consumers will make decisions about care and services for themselves and for the family unit. These decisions involve how to deal with consuming limited resources and how selection or purchasing decisions are made. [5]

Information asymmetry (an imbalance in information) is a particularly important aspect of information gathering, selection and decision-making regarding the engagement and use of healthcare services and facilities. [6] Healthcare systems in most countries are major undertakings and the complexity of those systems creates information asymmetry for consumers.

Health consumers (patients, clients, residents and the general community) have a landscape of options and issues available to support decision-making in relation to acquiring healthcare and health system support.[7,8] Key issues of experience, satisfaction and general expectations facilitate personal understanding and the building of a repertoire of individual and wider experiences. [9] Health, aged care and social care are specifically focused on individual and interpersonal relationships.[10] Engagement between consumers and clinicians forms an important relationship and therefore platform, on which to base assessment of choice for subsequent and prospective engagement with clinicians and practitioners. Consumers are aware of several third-party agents and agencies in the health sector (government, insurers, regulators and manufacturers) and take cues and have reliance on that 
and involvement of health consumers. Consumer knowledge, experience and expectations concerning the quality and safety of services require deeper skills on how to assess and articulate their requirements.

The purpose of this research was to understand current information sources, determinants of quality discernment and decision-making factors by consumers in the Australian community in relation to healthcare. This provides a benchmark on current understanding to inform an improvement and development agenda.

\section{METHODS}

A content analysis of transcripts from a national telephone interview survey was undertaken. A structured survey was developed to elicit information from the general community on sources of information, factors affecting quality assurance determination, indicators deployed in decision-making about obtaining services, as well as a general perception of the overall safety of the healthcare system (Table 1). Open ended questions were used to seek information from survey participants about the information sources they use for health related matters and in how they assess quality of care and services.

Computer Assisted Telephone Interviewing (CATI) provided the opportunity to administer a 15-question survey instrument in the Australian community to 200 participants aged 18 years and older. CATI (17) provides an efficient and accurate qualitative surveying method enabling wide coverage for responses from across the country by collecting responses, views and experiences from interviewees when the interviewer follows a survey script of open ended questions (Table 1). Telephone interviewing has been established as a methodologically viable and valuable data collection technique in qualitative research.[18] A series of strategies to enhance the use of CATI were developed and deployed including development of an interview script, validated questions that were previously piloted and engagement of experienced interviewers in a research and marketing call centre.[19]

For the purpose of this study, questions relating to quality assessment and information seeking were analysed. In the delivery of this survey, community members were invited to provide several responses to questions about current and suggested information and information sources relating to the healthcare system. Survey questions used are found in Table 1. First and second responses were obtained by asking all respondents to provide their main response and then the question was repeated to obtain any subsequent or second responses. Responses to these open-ended questions were grouped and summarised to provide themes and issues regarding use, experience and access to information on the healthcare system, health practitioners and health organisation providers. The survey respondent sample was similar to the population distribution by state/territory in Australia and age distribution was similar for the Australian population except the 25-34 age groups was under represented and the 6574 and 75-84 age groups overrepresented to the Australian population (Table 2).

\section{TABLE 1; TELEPHONE SUREVY INTERVIEW QUESTIONS - QUALITY AND INNFRMATION}

\begin{tabular}{l}
$\begin{array}{l}\text { How do you measure the quality of healthcare services (such as provided by doctors; } \\
\text { hospital; community clinics et cetera)? }\end{array}$ \\
\hline $\begin{array}{l}\text { What things are important to you when you choose a doctor, hospital or community health } \\
\text { service to receive care and treatment from? }\end{array}$ \\
\hline $\begin{array}{l}\text { What would you want to do to have a say or voice in quality assurance or improvement in } \\
\text { healthcare services provided? }\end{array}$ \\
\hline $\begin{array}{l}\text { What information about the quality and safety of the health care system do you want to } \\
\text { receive and how do you want that provided to you? }\end{array}$ \\
\hline $\begin{array}{l}\text { Do you think the healthcare system (doctors, hospitals, clinics) are safe and how do you } \\
\text { decide that? }\end{array}$ \\
\hline $\begin{array}{l}\text { Do you know about the "MyHospitals" website provided by the Australian government? } \\
\text { (www.myhospitals.gov.au) } \\
\text { and if you have used the website then - } \\
\text { What information did you look up on the 'MyHospitals' website } \\
\text { When was the last time you looked up information on the 'MyHospitals' website? }\end{array}$ \\
\hline
\end{tabular}


Conventional content analysis of the data was undertaken $[20,21]$ to determine any themes or patterns across the data set obtained from the telephone interviews. A series of codes were generated by the researcher to classify and categorise respondents' responses to questions. Themes have been presented with frequency tables to provide information on the evidence provided from respondents in this national survey.

Ethics approval, in line with National Health and Medical Research Council standards, was received from an appropriate Australian university Human Research Ethics Committee (HREC 2019/554).

\section{RESULTS}

This national survey returned 200 completed telephone surveys that were analysed by the CATI survey system, SPSS software (22) and the researcher. Table 2 sets out the distribution for respondents which demonstrates representation from across all age groups, by sex and residence across all states and territories in the country. Respondents were female (58.0\%) and male (42.0\%); representative of Australian age cohorts aged 18 years and older; and located in all states and territories in the country. Respondents highest completed education achievements were Year 10 (24\%); Year 12 (14.5\%); degree (32.5\%); postgraduate degree (11.5\%); and $4.5 \%$ had incomplete vocational and university studies.

TABLE 2: SURVEY RESPONDENTS; AGE, SEX AND NATIONAL DISTRIBUTION

\begin{tabular}{|c|c|c|c|c|c|}
\hline \multicolumn{6}{|c|}{ Percentage of Respondents Surveyed and Australian Population } \\
\hline & \multicolumn{3}{|c|}{$\begin{array}{l}\text { Survey Respondents } \\
\qquad(\mathrm{n}=\mathbf{2 0 0 )}\end{array}$} & \multirow{2}{*}{$\begin{array}{c}\text { Survey } \\
\text { Group } \\
\%\end{array}$} & \multirow{2}{*}{$\begin{array}{c}\begin{array}{c}\text { Australian } \\
\text { Population }^{+}\end{array} \\
\% \\
\end{array}$} \\
\hline Year Group & Male & Female & Total & & \\
\hline $18-24$ & 3 & 8 & 11 & 5.5 & 9.4 \\
\hline $25-34$ & 9 & 7 & 16 & 8.0 & 15.0 \\
\hline $35-44$ & 14 & 18 & 32 & 16.0 & 13.3 \\
\hline $45-54$ & 14 & 24 & 38 & 19.0 & 12.7 \\
\hline $55-64$ & 16 & 19 & 35 & 17.5 & 11.6 \\
\hline $65-74$ & 16 & 24 & 40 & 20.0 & 9.0 \\
\hline $75-84$ & 12 & 10 & 22 & 11.0 & 4.9 \\
\hline \multirow[t]{2}{*}{85 and over } & 0 & 6 & 6 & 3.0 & 2.0 \\
\hline & 84 & 116 & 200 & 100.0 & 100.0 \\
\hline
\end{tabular}

\begin{tabular}{|l|c|c|}
\hline \multicolumn{3}{|c|}{$\begin{array}{c}\text { Percentage of Respondents } \\
\text { Surveyed and Australian } \\
\text { Populations }\end{array}$} \\
\hline State & $\begin{array}{c}\text { Survey } \\
\text { Group }\end{array}$ & $\begin{array}{c}\text { Australian } \\
\text { Population }\end{array}$ \\
\hline & $\%$ & $\%$ \\
\hline ACT & 1.5 & 1.7 \\
\hline NT & 1.0 & 1.0 \\
\hline NSW & 33.0 & 31.9 \\
\hline QId & 24.5 & 20.1 \\
\hline SA & 5.0 & 6.9 \\
\hline Tas & 2.0 & 2.1 \\
\hline Vic & 23.5 & 26.0 \\
\hline WA & 9.5 & 10.3 \\
\hline & 100.0 & 100.0 \\
\hline
\end{tabular}

*ABS Estimated Australian resident population at 30 June 2019 (31010do002_2019912)

TABLE 3: MEASURES OF SYSTEM AND SERVICE QUALITY AND IMPORTANT ATTRIBUTES WHEN CHOOSING DOCTORS, HOSPITALS AND COMMUNITY HEALTH SERVICES FOR CARE AND TREATMENT

\begin{tabular}{|c|c|c|c|c|c|c|c|c|c|}
\hline \multicolumn{5}{|c|}{ Respondent's Measures of Quality of Healthcare Services } & \multicolumn{5}{|c|}{$\begin{array}{l}\text { Factors Important to Respondents in Choosing Doctors, Hospital } \\
\text { and Community Health Services for Care and Treatment }\end{array}$} \\
\hline & \multicolumn{2}{|c|}{$\begin{array}{c}\text { First } \\
\text { Response }\end{array}$} & \multicolumn{2}{|c|}{$\begin{array}{c}\text { Second } \\
\text { Response }\end{array}$} & & \multicolumn{2}{|c|}{$\begin{array}{c}\text { First } \\
\text { Response }\end{array}$} & \multicolumn{2}{|c|}{$\begin{array}{c}\text { Second } \\
\text { Response }\end{array}$} \\
\hline & $n$ & $\%$ & $n$ & $\%$ & & $n$ & $\%$ & $n$ & $\%$ \\
\hline Reputation & 60 & 30.0 & 29 & 14.5 & Reputation & 48 & 24.0 & 28 & 14.0 \\
\hline Respect and Interest in $\mathrm{Me}$ & 38 & 19.0 & 20 & 10.0 & Qualifications/Accreditation & 27 & 13.5 & 32 & 16.0 \\
\hline Doctor's Referral/Advice & 27 & 13.5 & 27 & 13.5 & Location & 26 & 13.0 & 29 & 14.5 \\
\hline Waiting Times & 14 & 7.0 & 21 & 10.5 & Waiting Times & 22 & 11.0 & 10 & 5.0 \\
\hline Experience and Approach & 12 & 6.0 & 8 & 4.0 & Communication/Explanation Abilities & 14 & 7.0 & 5 & 2.5 \\
\hline Treatment Outcomes & 6 & 3.0 & 4 & 2.0 & Approachability/Attitude & 14 & 7.0 & 16 & 8.0 \\
\hline \multirow[t]{3}{*}{ Safety Reports } & 4 & 2.0 & 3 & 1.5 & Listening/Understanding Capabilities & 10 & 5.0 & 6 & 3.0 \\
\hline & & & & & Knowledge/Treatment Capability & 10 & 5.0 & 4 & 2.0 \\
\hline & & & & & \begin{tabular}{|l|} 
Service Outcomes/Experiences \\
\end{tabular} & 4 & 2.0 & 1 & 0.5 \\
\hline Other NEC & 21 & 10.5 & 14 & 7.0 & Other NEC ${ }^{\#}$ & 17 & 8.5 & 12 & 6.0 \\
\hline \multirow[t]{2}{*}{ Don't Know/None Identified } & 18 & 9.0 & 74 & 37.0 & Don't Know/None Identified & 8 & 4.0 & 57 & 28.5 \\
\hline & 200 & 100.0 & 200 & 100.0 & & 200 & 100.0 & 200 & 100.0 \\
\hline
\end{tabular}




\section{RELATIONSHIP AND RELATIONSHIP BUILDING WITH CARE PROVIDER}

Respondents identified several key measures to do with the importance of relationship building when they assess quality of healthcare services (Table 3). For example, one respondent highlighted the need for "Interest and relationship with you". Another reported on expectations as "If it feels like they're asking the right questions and they're being thorough". This was supported by another respondent who commented: "Rapport, believing you're being heard, knowing there's concern about your position".

Clearly, relationship building, good rapport and thoroughness are important characteristics when making healthcare delivery decisions.

For the first responses to the question on use of quality measures, $9.0 \%$ of respondents did not know or were unable to identify a quality measure. Almost one third of respondents (30.0\%; $n=60$ ) reported the reputation of a service provider as the most significant measure of quality of healthcare services. This was followed by respondents identifying and assessing respect and interest shown by service providers and a referring doctor's recommendation and advice (19.0\%; $n=38$ and $13.5 \% ; n=27$, respectively) as the next most important measures of quality.

\section{REPUTATION, COMMUNICATIONS AND INTERPERSONAL RELATIONSHIPS}

Reputation was also identified as the most important factor when choosing a health service provider. The next most significant criteria utilised for selecting a care provider varied from the overall measures used in quality assessment; individuals highlighted qualifications and service provider accreditation (13.5\%; $n=27)$, proximity or location (13.0\%; $\mathrm{n}=26$ ) and access waiting times (11.0\%; $\mathrm{n}=22$ ) as reasons for choosing service providers. Only a small percentage of respondents $(4.0 \% ; n=8)$ were unable to identify a possible reason for selecting service providers. Communications was highlighted as an important factor is choosing and accessing care as well as in considering previous service experiences. One respondent set out the importance of advanced communication skills: "How thorough they are in answering my questions". One respondent spoke of engagement as "Interest and relationship with you" and another reiterated this citing: "Interest in me, the relationship they build".
Beliefs, understanding or opinions (reputation) appear important for most survey respondents in assessing quality and effectiveness of healthcare practitioners and providers, as well as being key determining factors in choosing particular health services for individual care. Respondents formed these opinions and established reputation thoughts by gathering different information. One survey respondent stated: "A lot of the times the references from other people that have used the same service". Another respondent stated they looked at published materials and combined that with further follow up: "Look for reviews online and see if there is anyone I knew and ask for their input".

Respondents noted previous personal experiences, as well as the experiences of others, influenced their choice of healthcare practitioner. Choosing service providers also involves pragmatic decision-making factors such as waiting times and location (travel distance). Lower frequency assessment criteria (Table 3 as Other Not Elsewhere Classified (NEC)) included issues of identified efficiency, costs, reported complaints and practitioner gender. Respondent actions in combining information and advice was exhibited by one survey respondent reporting on their information gathering as: "From their knowledge and qualifications".

\section{CONSULTATION AND INVOLVEMENT IN HEALTHCARE DELIVERY DEVELOPMENT}

Survey respondents were questioned about their desire and requirements to be consulted on quality assurance and improvement aspects of the delivery of healthcare services. Table 4 highlights that for almost half of those interviewed (40.0\%; $n=80$ ), the opportunity to respond to surveys, and evaluation tools and instruments was considered an important way to communicate their views and opinions. Almost $20 \%$ of respondents $(n=39)$ articulated their interest and capacity to communicate directly by email or correspondence to individuals and organisations concerning their views on quality issues in healthcare. A relatively high proportion of respondents $(18.5 \% ; n=37)$ did not know or identify a view or position about how they would want to have a voice on quality agenda matters. In relation to the identification of the types and methods of information delivery to respondents (Table 4), the key measures requested were the availability of ratings or rankings on practitioners' and providers' relationships with patients as well as performance data such as infection, injury and complaint rates. Information about performance and outcomes by way of measures of access and service 
performance were seen as very important by respondents. For availability and provision of information on quality and safety, a relatively high proportion of respondents $22.5 \%$; $n=45$ ) did not know or were unable to identify quality performance information sources. A spectrum of specific information topics including hygiene and cleanliness, financial accountability, administrative procedures and additional information on existing third-party websites were also identified within Table 4 (as Other Not Elsewhere Classified (NEC)).

\section{TABLE 4: OPPORTUNITIES IDENTIFIED FOR SAY OR VOKE ON QUALITY ASSURANCE AND IMPROVEMENT AND RECOMMENDED INFORMATION PROVISION TYPES AND FORMAT}

\begin{tabular}{|l|cc|cc|}
\hline \multicolumn{5}{|c|}{ Respondent's Wants on Say or Voice About Quality } \\
Assurance or Improvement in Healthcare Services Provided \\
\hline & \multicolumn{2}{|c|}{ First } & \multicolumn{2}{c|}{ Second } \\
\cline { 2 - 5 } & $n$ & $\%$ & $n$ & $\%$ \\
\hline Respond to survey/evaluation & 80 & 40.0 & 14 & 7.0 \\
\hline Communicate via email/letter & 39 & 19.5 & 8 & 4.0 \\
\hline Verbal contact to Service Provider & 12 & 6.0 & 0 & \\
\hline Write Internet Review & 8 & 4.0 & 14 & 7.0 \\
\hline & & & & \\
& & & & \\
\hline Other NEC & 24 & 12.0 & 10 & 5.0 \\
\hline Don't Know/None Identified & 37 & 18.5 & 154 & 77.0 \\
\hline & 200 & 100.0 & 200 & 100.0 \\
\hline
\end{tabular}

\begin{tabular}{|l|cc|cc|}
\hline \multicolumn{5}{|c|}{$\begin{array}{c}\text { Respondents Requests for Information on Quality and Safety } \\
\text { on the Health Care System }\end{array}$} \\
\cline { 2 - 6 } & \multicolumn{2}{|c|}{ First } & \multicolumn{2}{c|}{ Second } \\
\cline { 2 - 6 } & $n$ & $\%$ & $n$ & $\%$ \\
\hline Ratings on doctor/care provider patient relationships & 31 & 15.5 & 18 & 9.0 \\
\hline Performance (e.g. infection, injury, complaints rates) & 28 & 14.0 & 14 & 7.0 \\
\hline Effectiveness care/treatment organisation/co-ordination & 19 & 9.5 & 17 & 8.5 \\
\hline Rankings of health personnel and facilities & 18 & 9.0 & 12 & 6.0 \\
\hline Safety Ratings on Service Providers & 11 & 5.5 & 13 & 6.5 \\
\hline Waiting Times & 11 & 5.5 & 10 & 5.0 \\
\hline Other NEC & 37 & 18.5 & 6 & 3.0 \\
\hline Don't Know/None Identified & 45 & 22.5 & 110 & 55.0 \\
\hline & 200 & 100.0 & 200 & 100.0 \\
\hline
\end{tabular}

TABLE 5: ASSESSEMENT OF OVERALL SAFETY OF THE AUSTRALIAN HEALTHCARE SYSTEM AND PRINCIPLE DECIDING FACTOR

\begin{tabular}{|c|c|c|}
\hline \multicolumn{3}{|c|}{$\begin{array}{l}\text { (a) Do you think the Healthcare System (doctors, hospitals, } \\
\text { clinics) is safe? }\end{array}$} \\
\hline & $n$ & $\%$ \\
\hline Yes & 172 & 86.0 \\
\hline No & 14 & 7.0 \\
\hline Unsure & 14 & 7.0 \\
\hline & 200 & 100.0 \\
\hline $\begin{array}{l}\text { (b) What was the primary reason or } \\
\text { experience that makes you think that? }\end{array}$ & $n$ & $\%$ \\
\hline Own Experience with Health Care System & 157 & 78.5 \\
\hline Family Members Assessment & 10 & 5.0 \\
\hline Friends and Colleagues Assessment & 6 & 3.0 \\
\hline Media Reports & 7 & 3.5 \\
\hline Government Reports/Publications & 5 & 2.5 \\
\hline Compared to Overseas Healthcare Systems & 3 & 1.5 \\
\hline Other Not Elsewhere Classified (NEC) & 9 & 4.5 \\
\hline \multirow[t]{2}{*}{ Don't Know/None Identified } & 3 & 1.5 \\
\hline & 200 & 100.0 \\
\hline
\end{tabular}

\section{SOURCES OF INFORMATION ON HEALTH SERVICES}

A series of open-ended questions incorporated into the telephone survey gathered information regarding respondents' primary source of information about health issues. In addition to the specific questions on quality and information seeking, 9 questions were asked about where respondents might seek information on obtaining specific services and health information or advice. Open-ended questions sought details of the main person or source of information used by consumers to find a doctor for care and treatment; information about prescription and nonprescription drugs; access to counselling services; information about health issues including smoking cessation and weight loss or gain; as well as care and treatment alternatives. An aggregation of responses to these questions showed information and access was obtained from doctors (31.3\%), the internet $(29.8 \%)$ and pharmacists (retail and hospital) (10.1\%). A second level of information sources included friends and colleagues (3.3\%), telephone helplines (1.9\%) and family members (1.6\%). Other identified sources, at lower levels of utilisation, 
included health professionals (doctors), hospital and healthcare agencies, professional health bodies, government and department agencies.

Survey respondents were asked about their utilisation of the MyHospitals website.[13] Only a relatively small percentage of those surveyed (14.5\%; $n=29$ ) reported awareness of this information source where $3.0 \%$ of respondents were unsure if they had heard of the website. For those respondents who reported use of the website $(n=9)$ this was reported as mostly occurring within the previous month or more than one year ago. Respondents who used the website stated their main reason was to find local healthcare provider details for themselves or their family, or to obtain general information about hospital services and facilities. Respondents who indicated they had used the site for general information did not report use in relation to accessing performance information on quality, safety or care outcomes.

\section{HEALTH SYSTEM SAFETY AND TRUST IN HEALTHCARE DELIVERY}

Survey respondents were asked for their overall perception of the general safety of the Australian healthcare system relating to doctors, hospitals and clinics. The majority of responses were positive towards this question with one respondent highlighting both expectations and opportunity for choice: "Thoroughness - if I go with something and I'm not completely happy I want further treatment (elsewhere)" and another respondent setting out international comparative evaluation was their basis for determining that the Australian system was of quality: "In comparing to other countries".

Table 5 highlights that the majority of respondents $186.0 \%$; $\mathrm{n}=172$ ) believe the system is a safe one, justified through their own experiences with different services, elements and parts of the Australian healthcare system. Respondents assessed safety across input, environment, service type and again, international comparison: "It is safe because of the amount of money put into it. Also, we don't have much else"; "Depends on where you live - access to medical care"; and a respondent said they would make international system comparisons "Other countries compared to Australia". One respondent reported overall in their survey responses but also included comment on their perception of quality in a particular sector or part of the care continuum with staffing levels and staff qualifications needing improvement in aged care: "No - nursing homes and aged care facilities - in general, staffing levels and qualifications of staff".

\section{DISCUSSION}

This research project was intended to provide an understanding on current information sources, quality discernment and decision-making factors by consumers in the Australian community in relation to healthcare services; to establish a benchmark on current understanding; and to contribute to improvement and development around consumers and quality and safety.

Results from this research highlighted similar responses to findings detailed in the literature.[23-25] Respondents in this study highlighted the importance of clinician and patient (consumer) relationships, as well as the critical nature of communications to support decision-making when using health services and understanding quality and value issues.[23] Information providers and gatekeepers of performance information are important to consumers and the impact of rapid access to information through the internet provides a vital source of communication and information sharing now and for the future.[24] An important development area is in understanding and acknowledgement that the public, or healthcare consumers, is a significant and major audience for information. Public information provision (regarding items such as current quality, performance and rankings information) is an avenue that requires particular strengthening and expansion for public consumption. [25]

Survey respondents demonstrated value and capacity in using different types and sources of information when making decisions about quality of services and access to care. Respondents reported that their experience, interpersonal engagement with care givers and third-party advice figure as important sources of information. These types of information and sources are important ways through which consumers discern both quality and performance related to service provision as well as in making direct or indirect choices about purchasing healthcare services. Consumers have capacity and appetite for information and will use it. The findings in this research provide important development areas concerning information supply including about ratings, rankings, reviews and the experience of others. 
This research shows that respondents rely on the interpretations of individuals (health professionals, families and friends), the internet and a range of other information sources to build a picture and understanding of specific services and the health system generally. Respondents use discrete selection criteria (waiting times, location and interpersonal skills of practitioners) in their decision-making.

\section{DETERMINING QUALITY}

Several important themes were identified by respondents in relation to measuring the quality of healthcare services. Fundamentally, reputation is developed by providers demonstrating technical abilities, appropriateness and capacity for undertaking service delivery activities against the wider principles of proper behaviour and conduct.

It is unclear from these survey results how respondents assess reputation (Table 3 ). However, when considering the other explicit reported measures used in quality of service determination (interpersonal, access, care outcomes and safety assessments), the literature suggests that technical, procedural and moral elements are used. [8, 23] Respondents reported on key elements and issues regarding their use of services and perception of the health system, with one respondent saying they "Monitor the effects of their recommendations...testing what they tell you with other sources" and another survey response reporting on care provider experience "Good people skills and knowledgeable enough to say when they don't know something".

A broader set of determinants was identified by respondents when choosing doctors, hospitals and community healthcare. These included a breakdown of interprofessional engagement actions (communications and explanation capacity, approachability and attitude, listening and comprehension capabilities, as well as technical capability assessment). These findings are consistent with research reported in the literature.[16]

\section{VOICE ON QUALITY AND INFORMATION}

Respondents identified key mechanisms through which they would prefer to have opportunities for assessment and a voice regarding quality issues in relation to healthcare. Fundamentally, preferences were for responding to surveys and other evaluation or assessment instruments. This indicates that structured formats and approaches are preferred. Respondents identified their preferred mechanisms to provide feedback and assessment of healthcare quality issues. Approximately $20 \%$ of respondents indicated that they were prepared to communicate via email or written correspondence regarding their experiences and expectations.

In relation to the information required by consumers, $30 \%$ of respondents said that performance information, such as ratings of practitioner and provider performance regarding patient relationships and measurable outcomes would be valuable in their decision-making. The range of information requested covers interpersonal connections between healthcare providers and consumers, details of processes and outcomes of care and treatment, as well as access to care and waiting times. The strong preference for ratings and rankings may be indicative of consumers' desire for both information and comparison with expected performance standards. Previous research has identified need for descriptive performance information and interpretation of its meaning and value.[7]

\section{LISTENING AND ENGAGING}

A key finding from this research has been the respondents' desire for communication and interpersonal connections between care providers and consumers. These are key measures used for assessing performance and value of care, as well as being instrumental to decisions to seek out health service provision. Respondents articulated the importance of communication skills and the professional provider/consumer relationship. Issues of interpersonal connectivity by consumers with their care providers is reported in other research but what was important from this study was the high prioritisation of communications and interpersonal connectivity in evaluating and choosing health services.

\section{LIMITATION FOR THIS STUDY}

The sample size for this research was moderate but it was large enough (the study included respondents across all age groups and representation from each state and territory) to detect and identify key issues and themes regarding the behaviours, needs and wants of consumers in relation to healthcare quality and information.

Qualitative research is both context and time bound and these findings are not generalisable, but they may be transferable to different contexts in health service delivery.

Responder bias was mitigated in this study by using plain and simple language in the development of survey 
questions. Researcher bias has been mitigated through the use of independent telephone survey interviewers; a survey script that was validated by a panel; and the invitation to interviewees from a random national call list.

\section{FURTHER RESEARCH}

Reputation of service providers and organisations were identified as key evaluation and assessment factors for quality determination by respondents. Further research around key elements of processes associated with reputation and meaningfulness to consumers would be appropriate. This would assist to define and deepen understanding around the particular bridging factors in consumers' understanding and determination of quality of health service delivery. Comparative international studies would be useful in understanding different community and cultural perspectives of health consumers. A longitudinal study on consumer expectations in relation to healthcare quality and safety would be valuable in relation to changes in consumer engagement with required and provided information.

\section{CONCLUSION}

Reputation of individual providers and organisations figured as being of high importance to consumers in this study. This provides significant opportunities for individuals and organisations to promote appropriate technical, procedural and moral reputations to health consumers. The purpose of this research was to understand current information sources, determinants of quality discernment and decision-making factors by consumers in the Australian community in relation to healthcare.

This research advances our understanding of how Australian consumers understand and view quality and the quality assessment of health services. Personal patient relationships, communications and other interpersonal connections are not only key measures by which quality is assessed but are also preferred sources when making decisions about healthcare providers.

Consumers value third-party interpretation and commentary. Performance indicators and rankings (and associated interpretation) continue to be used by consumers when decision-making in relation to healthcare.

Reputation of individual providers and organisations figured as being of high importance to consumers in this study. This provides significant opportunities for individuals and organisations to promote appropriate technical, procedural and moral reputations to health consumers. The purpose of this research was to understand current information sources, determinants of quality discernment and decision-making factors by consumers in the Australian community in relation to healthcare.

\section{References}

1. Allen-Duck A, Robinson JC, Stewart MW. Healthcare Quality: A Concept Analysis. Nurs Forum. 2017;52(4):377-86.

2. Mitchell P, Cribb A, Entwistle VA. Defining What is Good: Pluralism and Healthcare Quality. Kennedy Institute of Ethics journal. 2019;29(4):367-88.

3. Williams ES, Savage GT, Patrician PA. Quality Improvement Basics. In: Buchbinder SB, Shanks NH, editors. Introduction to Health Care Management. Burlington, MA: Jones \& Bartlett Learning; 2017.

4. Sirgy MJ, Lee D-J, Yu GB. Consumer Sovereignty in Healthcare: Fact or Fiction? Journal of Business Ethics. $2011 ; 101(3): 459-74$

5. Taylor EA, Carman KG, Lopez A, Muchow AN, Roshan $\mathrm{P}$, Eibner $\mathrm{C}$. Consumer Decisionmaking in the Health Care Marketplace. Santa Monica, California: RAND Corporation; 2016.

6. Major I. Two-Sided Information Asymmetry in the Healthcare Industry. International advances in economic research. 2019;25(2):177-93.

7. Australian Commission on Safety and Quaity in Health Care. Public reporting of safety and quality in public and private hospitals. Sydney: ACSQHC; 2019.

8. Damman OC, Hendriks M, Rademakers J, Delnoij DMJ, Groenewegen PP. How do healthcare consumers process and evaluate comparative healthcare information? A qualitative study using cognitive interviews. BMC Public Health. 2009;9(1):423.

9. Grace S, Bradbury J, Avila C, Du Chesne A. 'The healthcare system is not designed around my needs': How healthcare consumers self-integrate conventional and complementary healthcare services. Complementary therapies in clinical practice. 2018;32:151-6. 
10. Gusmano MK, Maschke KJ, Solomon MZ. PatientCentered Care, Yes; Patients As Consumers, No. Health Affairs. 2019;38(3):368-73.

11. Healy J. Improving health care safety and quality: reluctant regulators. Surrey, UK E;Burlington, VT;: Ashgate; 2011.

12. Taylor M, Hill S. Consumer Expectations and Healthcare in Australia. Sydney: Deeble Institute; 2014.

13. Australian Institute of Health and Welfare. MyHospitals [Australian public and private hospital information]. Australian Government. AlHW.; 2020 [Available from: https://www.aihw.gov.au/reports-data/myhospitals .

14. Ancona D. Sensemaking: Framing and Acting in the Unknown. In: Snook S, Nohria N, Khurana R, editors. The handbook for teaching leadership : knowing, doing, and being. Los Angeles: SAGE Publications; 2012. p. 319.

15. Dervin B. Sense-making theory and practice: an overview of user interests in knowledge seeking and use. Journal of knowledge management. 1998;2(2):3646.

16. Abbasi-Moghaddam MA, Zarei E, Bagherzadeh R, Dargahi $H$, Farrokhi P. Evaluation of service quality from patients' viewpoint. BMC Health Services Research. 2019;19:NA.

17. Kelly P. Computer-Assisted Telephone Interviewing (CATI) In: Lavrakas PJ, editor. Encyclopedia of Survey Research Methods. Thousand Oaks: Sage Publications, Inc.; 2008.

18. Sweet L. Telephone interviewing: is it compatible with interpretive phenomenological research? Contemporary nurse : a journal for the Australian nursing profession. 2014;12(1):58-63.

19. Faroog MB, De Villiers C. Telephonic qualitative research interviews: When to consider them and how to do them. Meditari Accountancy Research. 2017.

20. Nevendorf K.A. Defining Content Analysis. In: Neuendorf KA, editor. The Content Analysisi Guidebook. Los Angeles: Sage; 2017.

21. Hsieh H-F, Shannon S.E. Three Approaches to Qualitative Content Analysis. Qualitative health research. 2005;15(9):1277-88.

22. IBM Corporation. IBM SPSS Statistics for Windows, Version 26.0. 2019
23. AP-NORC Center for Public Affairs Research. Finding Quality Doctors: How Americans Evaluate Provider Quality in the United States. Chicago: AP-NORC Center for Public Affairs Research; 2014.

24. Burns P, Jones SC, Iverson DC, Caputi P. Where do older Australians receive their health information? Health information sources and their perceived reliability. Journal of Nursing Education and Practice. 2013;3(12):60 - 9.

25. Canaway R, Bismark M, Dunt D, Kelaher M. Perceived barriers to effective implementation of public reporting of hospital performance data in Australia: a qualitative study. BMC Health Services Research. $2017 ; 17(1): 391$. 